\title{
Memória, patrimônio e informação: diálogos em uma disciplina nuclear ${ }^{1}$
}

\author{
Luiz Henrique Assis Garcia ${ }^{I}$ \\ https://orcid.org/0000-0003-0539-4566 \\ ${ }^{I}$ Universidade Federal de Minas Gerais, Belo Horizonte, MG, Brasil. \\ Graduado, mestre e doutor em História pela UFMG. \\ Professor Associado do curso de graduação em Museologia e Professor \\ Permanente do PPG-CI da Escola de Ciência da Informação da UFMG. \\ Coordenador do Grupo de Pesquisa ESTOPIM.
}

http://dx.doi.org/10.1590/1981-5344/3898

A reformulação do Programa de Pós-Graduação em Ciência da Informação da ECI-UFMG envolveu a inserção de novos colaboradores e a necessidade de repensar o projeto pedagógico. Neste contexto, decidiu-se pela concepção de disciplinas nucleares, para criar um solo compartilhado que pudesse alavancar o trabalho de reflexão e investigação. No âmbito da linha de pesquisa "Memória social, patrimônio e produção do conhecimento", envolvi-me ativamente na concepção e oferta da disciplina "Memória, patrimônio e informação". Proponho-me aqui a examinar a proposta que a norteia, centrada no duplo intuito de oferecer uma base sólida para a compreensão da constituição e transformação dos campos que coloca em destaque e igualmente oferecer um apanhado representativo das pesquisas mais inovadoras e temas candentes na atualidade. Traçaremos uma síntese seguindo o percurso das aulas expositivas e seminários de modo a explicitar o fio condutor do curso, para concluir com uma apreciação de conjunto sobre o que foi feito na disciplina. Como mostraremos, a reformulação efetivada em 2016, portanto, não surgiu no vazio, e sim em terreno que já recebera as primeiras sementes. Uma disciplina nuclear representa o melhor adubo para que tenhamos ótimas safras no futuro próximo.

\footnotetext{
${ }^{1}$ Este trabalho é fruto direto de disciplina lecionada junto ao PPG-CI no 20 semestre de 2017 , e deixo aqui meu agradecimento aos discentes que a cursaram, em um ambiente em que imperaram a troca intelectual e a boa convivência. Uma pequena parte sobre os estudos de memória foi apresentada (e bem acolhida) no evento CTCM em Recife (GARCIA, 2011). O texto também incorpora leituras que estão sendo feitas no âmbito do projeto de pesquisa Patrimônio urbano e música popular: lugares e coleções, apoiado pela FAPEMIG.
} 
Palavras-chave: Memória. Patrimônio. Ciência da Informação. Ensino de Pós-Graduação.

\section{Memory, heritage and information: dialogues within a core discipline}

The reformulation of ECI-UFMG's Graduate Program in Information Science involved the insertion of new collaborators and the need to rethink the pedagogical project. In this context, it was decided to create core disciplines, to create a shared ground that could support the work of reflection and investigation. Within the scope of the research line "Social memory, heritage and knowledge production", I was actively involved in the design and offering of the discipline "Memory, heritage and information". I propose here to examine its guidelines, centered on both providing a solid basis for the understanding of the constitution and transformation of the fields that it emphasizes and offering a representative recollection of most innovative researches and hot topics at the present time. We will draw a synthesis of the expository classes and seminars in order to explain its main course, to conclude with a general appreciation of what was done within the discipline. As we shall show, the reformulation carried out in 2016, therefore, did not emerge in the void, but on land that had already received the first seeds. A nuclear discipline represents the best fertilizer so that we can harvest good crops in the near future.

Keywords: Memory. Heritage. Information Science. Graduate Program teaching.

Recebido em 12.03.2019 Aceito em 12.03.2019

\section{Introdução}

A reformulação do Programa de Pós-Graduação em Ciência da Informação (PPG-CI) da Escola de Ciência da Informação da Universidade Federal de Minas Gerais (ECI-UFMG), com a adoção da área de concentração Informação, Mediação e Cultura e da formulação de três novas linhas de pesquisa - Memória social, patrimônio e produção do conhecimento; Políticas públicas e organização da informação e Usuários, gestão do conhecimento e práticas informacionais - foi produto de consideráveis esforços. Neste contexto, com a inserção de novos 
colaboradores e a necessidade de repensar o projeto pedagógico, decidiuse pela concepção de disciplinas nucleares, para criar um solo compartilhado a partir do qual o corpo docente e discente do Programa pudesse alavancar o trabalho de reflexão e investigação no âmbito de cada linha de pesquisa. Envolvi-me ativamente na concepção da disciplina Memória, patrimônio e informação, e proponho-me aqui a examinar a proposta que a norteia, traçar um panorama dos principais temas abordados e encerrar relatando sobre a experiência inaugural de lecionála no segundo semestre de 2017.

É importante ressaltar que a transformação do Programa é entendida dentro de um processo maior, como pode ser constatado no que está narrado ao longo de vários artigos do número especial desta mesma revista, dentre aqueles o que escrevi em coautoria com colegas que, como eu, ingressaram na ECI nos concursos motivados pela criação, através do Programa de Apoio a Planos de Reestruturação e Expansão das Universidades Federais (REUNI), do curso de graduação em Museologia (JULIÃO; GARCIA; SABINO, 2015). Entre outros efeitos das novas graduações criadas, como era de se esperar, estava o aparecimento de novas linhas de investigação e atuação docente e novos perfis de profissionais sendo formados. Tanto estes últimos quanto aqueles já atuantes em órgãos e instituições vinculados aos campos do Patrimônio Cultural e da Memória foram passando a reconhecer na ECI um espaço de promoção dos debates que Ihes interessavam e de possibilidade para continuar sua formação acadêmica.

Noto que a sinergia entre graduação e pós-graduação foi uma das linhas de força que orientaram o projeto pedagógico reformulado do PPGCI. Acrescento que há resultados promissores nas aproximações evidentes entre os campos referidos acima e a Ciência da Informação, percebidas e ensaiadas dentro do próprio Programa antes mesmo da reformulação. Uma rápida consulta ao repositório de Dissertações e Teses do Sistema de Bibliotecas da UFMG evidencia esse movimento, especialmente concentrado na presente década. Encontramos respostas para buscas bem pormenorizadas como "memória social" (2); "memória coletiva" (3); "patrimônio cultural" (10); ou mais gerais como "museu" (13); "arquivo" (31); "acervo" (41). Trata-se de uma busca rápida cujo propósito é basicamente provar o ponto, e não há aqui qualquer pretensão de um estudo mais detalhado desse acervo que, por mais desejável, extrapola o escopo do presente artigo. Prossigo, portanto, no que me propus, apresentando a disciplina, para em seguida tratar de seus principais temas e procurar sintetizar o que foi a experiência obtida em sala de aula.

\section{Proposta norteadora da disciplina}

A disciplina Memória, patrimônio e informação traça um panorama que considera aproximações e diálogos a partir de diferentes perspectivas conceituais adotadas em torno dos campos da memória e do patrimônio, por variadas correntes de pensamento: a tradição da mnemônica 
(SAMUEL 1994; RICOEUR, 2007; YATES, 2007; WEIRINCH， 2001); as relações entre memória, narrativa e teoria crítica (BENJAMIN, 1985; 2007; GAGNEBIN, 1994; HUYSSEN, 2014; SELIGMANN-SILVA, 2008) a sociologia, a historiografia e a psicologia social que operaram com 0 conceito de memória social (HALBWACHS, 2006; BOSI, 1979; POLLACK, 1989); a introdução mais recente do conceito de memória cultural (ASSMANN, 2011; ERLL, 2011; RÜSEN, 2014); os estudos sobre a categoria de patrimônio e suas aplicações em diferentes contextos (ABREU; CHAGAS, 2003; GONÇALVES, 2002; JEUDY, 1990; LOWENTHAL, 1985); as pesquisas sobre dispositivos e práticas de representação e mediação e seus processos de institucionalização em sociedade (SILVA, 2002; SALGADO, 2013; LEAHY, 2011; GIEBELHAUSEN, 2012; SIMINE, 2013; MACDONALD, 2013). Tal aparato teórico embasa um debate envolvendo as relações entre passado/presente e história/memória; as disputas contemporâneas pela memória e a comodificação da nostalgia; as políticas de patrimônio e de rememoração/esquecimento; o impacto das Novas Tecnologias de Informação e Comunicação (NTICs) e as relações de poder no contexto da sociedade do espetáculo e das redes sociais em meio digital; as dinâmicas nos contextos institucionais de bibliotecas, arquivos e museus ou em espaços não institucionalizados; a construção da alteridade e da subjetividade na produção do conhecimento a partir da informação e da memória social ou cultural.

É preciso considerar que, dentro da organização da grade curricular, esta disciplina se insere no momento de estabelecimento de um "eixo formativo" que orienta as opções teóricas e metodológicas dos alunos após o cumprimento de disciplinas obrigatórias que consistem numa formação básica conceitual, dedicadas a apresentar o arcabouço do campo da Ciência da Informação, como Fundamentos da Ciência da Informação e Métodos e Técnicas de Pesquisa em Ciências Sociais Aplicadas (PROPOSTA..., 2016). O caráter nuclear da disciplina, assim, define-se no duplo intuito de oferecer uma base sólida para a compreensão da constituição e transformação dos campos que coloca em destaque, considerando inclusive seus pontos de contato, e igualmente oferecer um apanhado representativo das pesquisas mais inovadoras e dos temas de investigação mais candentes na atualidade. Desse modo o percurso das investigações ganha densidade e prepara o terreno para a verticalização das pesquisas específicas de dissertações, teses, artigos e trabalhos afins.

A bibliografia adotada procurou mesclar de forma equilibrada os estudos já consagrados e autores considerados clássicos com trabalhos contemporâneos que apresentam os conceitos discutidos em ação na pesquisa aplicada e também sinalizam os debates atuais e desafios candentes em face das transformações de nossa experiência social e histórica. Essa distribuição também é refletida pelos seminários propostos no cronograma de trabalho, sendo metade dedicada aos temas consagrados e categorias centrais (Conceito de memória social; $D a$ memória social à memória cultural; Políticas de memória e patrimônio no espaço público) e a outra metade a questões contemporâneas, tanto no plano teórico quanto na aplicação em pesquisa (Políticas de patrimônio e 
de rememoração/esquecimento; Ruína, perda, trauma; A comodificação da nostalgia). Este enfoque permitiu contemplar a diversidade de interesses de pesquisa dos alunos inseridos na linha de pesquisa, o que ficou claramente refletido nos trabalhos finais apresentados, cuja proposta era desenvolver uma versão inicial de capítulo de dissertação ou tese incorporando as discussões e autores envolvidos no programa da disciplina. A seguir apresento uma síntese seguindo o percurso das aulas expositivas e seminários de modo a explicitar o fio condutor do curso, para que em seguida seja possível uma apreciação de conjunto sobre o que foi feito na disciplina.

\section{A tradição da mnemônica e as relações entre memória, narrativa e teoria crítica}

Um ponto de partida válido para iniciar nossas considerações sobre a memória é a distinção traçada por Aristóteles entre lembrança (mneme) e recordação (anamnesis). Em sua perspectiva, a memória implica numa percepção que distingue o antes e o depois, o transcorrer do tempo, mas enquanto a lembrança simplesmente ocorreu, faz-se presente como evocação de uma ausência, a recordação é fruto de uma busca, de um percurso realizado pelo explorador do passado (RICOEUR, 2007, p. 3539).

Daí a retomada da distinção feita por Aristóteles. Ao ressaltar o sentido de anamnesis, Samuel considera a memória como forma de construir conhecimento, e propõe aproximar o trabalho de recordação daquele que realiza o historiador. Como mostra Hannah Arendt, isso já está sugerido pelo próprio Aristóteles quando pensa que as ações humanas, perecíveis, só podem perdurar pela intervenção da recordação, tarefa que atribuía tanto ao poeta quanto ao historiador (ARENDT, 2007, p. 72-74). A noção de recordação implica, portanto, na realização de algum tipo de investigação. Neste ponto, cabe a discussão feita por Paul Ricoeur sobre a noção de rastro, algo que remete à lembrança de uma presença ausente. Daí ele usar a imagem do desenho do animal ao explicar que uma inscrição ou registro tem dupla dimensão, enquanto ela própria e enquanto representação de outra coisa (RICOEUR, 2007, p. 36). Ainda que não se deva tomar a memória com o sentido platônico de cópia (eikon), não se deve tampouco vê-la como indistinta da imaginação:

$\mathrm{Na}$ apreensão da relação da memória à história, Ricoeur detecta a verdade como sendo o elemento comum entre ambas. Segundo esse autor, a busca do passado (característica da anamnese aristotélica), visando à exatidão, à fidelidade, à verdade, tende a invalidar a ideia, falsamente admitida na tradição filosófica, da equivalência da memória à imaginação. Se esta última se identifica com o irreal e com a ficção, a memória, apesar de sua fragilidade e de seus enganos, visa, ao contrário, à fidelidade e à verdade. A história reencontra, então, a memória nessa sua ambição da verdade (SILVA, 2002, p. 430).

É por esta seara que envereda Raphael Samuel quando afirma que a mnemônica, cujo suposto descobridor teria sido o poeta Simônides de 
Ceos, era a base do processo de aprendizagem na antiga Grécia. Neste sentido, vale acrescentar sua observação apoiada nos estudos de Frances Yates, de que a memória era a mãe de todas as pedagogias e serviu, em seu último grande florescimento na Renascença, de alicerce oculto para a arte e a ciência (SAMUEL, 1994, p. vii). A mnemônica, seguindo os princípios cuja elaboração atribuiu-se a Simônides, continuada pelos romanos e posteriormente revivida pelos escolásticos medievais - aliás, Yates (2007) fixa na Idade Média a origem efetiva da 'arte da memória' dava preferência à imagem e à sua fixação em um determinado lugar (SAMUEL, 1994, p. viii; SPENCE, 1986, p. 19-21). Assim, "[...] sua mnemônica implicava de preferência uma espécie de cartografia mental na qual o espaço, mais do que o tempo, fornecia os marcos significativos [...]" (SAMUEL, 1994, p. viii). Ou, como sintetiza Ricouer (2007, p. 76), "a ordem dos lugares preserva a ordem das coisas". John Kroiss, por sua vez, ressalta as ligações desta arte com a retórica, como na técnica recomendada por Quintiliano em seus manuais, de que o orador deveria organizar seu discurso posicionando os tópicos que desejasse recordar em diferentes cômodos de uma casa imaginária (KROISS, 2002, p. 152). Essa conexão é igualmente explorada por Jonathan D. Spence em $O$ palácio da memória de Matteo Ricci, ao mapear o contexto cultural e a formação religiosa de um missionário jesuíta que buscou aplicar a mnemônica para cristianizar os chineses no século XVI (SPENCE, 1986). Dante, na Divina Comédia, produz uma verdadeira topologia do Além (RICOUER, 2007, p. 78). De todo modo, os autores indicam a presença da arte da memória como organizadora do mundo, fosse na arquitetura dos templos que buscava "fixar a narrativa sagrada nas mentes dos iletrados" (SAMUEL, 1994 , p. viii), fosse na criação de diagramas concêntricos chamados "teatros da memória", sistemas astrologicamente orientados como os desenhos criados por Giulio Camillo nos anos 1540 que identificavam a verdadeira sabedoria à colocação do observador numa posição elevada (Spence, 1986, p. 37-38). Kroiss destaca também uma passagem de $A$ arte da memória, em que Frances Yates propõe que a história da mesma é chave importante para entender o surgimento do pensamento metodologicamente ordenado (KROISS, 2002, p. 152). São nexos fundamentais, portanto, para entender as formas de organização e recuperação do conhecimento.

O livro de Yates assinala como ponto de inflexão na história da arte da memória a invenção da imprensa, vendo nela uma das razões de seu declínio. Samuel, por sua vez, assinala, durante o Romantismo, a passagem de uma percepção "cósmica" para outra mais introspectiva, em que a memória se voltava para a escala do indivíduo e de seu círculo familiar, tendo como paisagem costumeira a casa da infância e enfatizando um senso de perda. Para o autor, o legado romântico se faria sentir na ideia de uma oposição entre memória, instintiva, subjetiva, falha, e história, guia pela razão e pela empiria, objetiva e segura. Tal oposição ele contesta, afirmando que há uma relação dialética entre as duas (SAMUEL, 1994, p. ix-X). Retomaremos esse tema mais adiante ao 
tratar da construção e circulação dos conceitos de memória social e memória cultural.

Ao refletir sobre o conceito de memória, não podemos, portanto, desconsiderar sua historicidade. É preciso, assim, entender que as relações entre o passado e o presente envolvidas na constituição do que chamamos memória articulam-se pela forma como são percebidas num dado tempo. Foi justamente esta a preocupação de Walter Benjamin ao longo de sua obra, ao tratar das condições de produção da narrativa nos tempos modernos e elaborar suas teses sobre a História. Neste sentido, devemos tomar os temas da perda da experiência e o declínio da narrativa no contexto da vida moderna de forma concomitante à sua crítica da noção de progresso e elaboração do materialismo histórico que propõe uma ruptura do tempo "homogêneo e vazio", e aproxima o historiador do trapeiro para recolher os restos e rememorar o que estava ameaçado de esquecimento, redimindo o passado através de sua atualização no presente.

Para Benjamin, a perda da experiência (erfahrung) relaciona-se ao declínio da narrativa, na medida em que aumentava a impossibilidade de partilha coletiva propiciada quando se ouvia ou contava uma história. Essa troca depende da existência de uma "comunidade de ouvintes" (BENJAMIN, 1985, p. 205), que rareia na medida em que o trabalho artesanal - que propicia a distensão psíquica em que o ouvinte se deixa gravar pela narração - é substituído pelo industrial e o tempo da tradição pelo tempo alienante do trabalho capitalista (GAGNEBIN, 1994, p. 61). A esse novo tempo correspondem outras formas de comunicação, como o romance e o jornal, que expressam o isolamento do indivíduo moderno e a lógica do consumo imputada na efêmera validação da informação, logo abandonada ao esquecimento (BENJAMIN, 1985, p. 107). No contexto da metrópole, do trabalho fragmentado da linha de montagem, da presença da multidão e da contínua exposição do indivíduo aos constantes choques impostos à sua consciência pelos estímulos externos, impossíveis de serem assimilados dentro do esquema simbólico tradicional, dá-se o amortecimento do que é experimentado pelo sujeito enquanto vivência (erlebnis), exclusivamente referida a sua existência solitária e avessa à narração. Vale considerarmos que a empreitada das Passagens, ao propor uma abordagem do século XIX a partir da leitura da fisionomia da metrópole moderna, constitui-se enquanto narrativa justamente pela constelação de reminiscências colecionadas por seu autor. É, portanto, uma estratégia que nos inspira na medida em que propõe uma refiguração da experiência urbana a partir de uma narração feita dos rastros que não queremos relegar ao esquecimento.

Daí a grande aproximação de Benjamin com a obra de Marcel Proust, autor no qual reconhece "[...] a mais alta expressão fisionômica que a crescente discrepância entre vida e poesia pode assumir" (BENJAMIN, 1985, p. 36). Em Proust ele identifica a possibilidade da rememoração (eingedenken) que não visa reconstituir um passado "de fato" e sim constituir, com o mecanismo da reminiscência, uma nova experiência narrada no presente através do ato de lembrar. Assim, 
Benjamin propõe o conceito de atualização, apontando a relação dialética entre o ocorrido e o agora, definindo a compreensão histórica como "[...] uma vida posterior do que é compreendido" (BENJAMIN, 2007, p. 502). Reflexões construídas num tempo de crise, em que a própria possibilidade de narrar é ameaçada, como aponta Gagnebin em sua análise do conto "A mensagem imperial", de Kafka, demonstrando finalmente que "O desmoronamento da tradição termina sendo, por fim, o único lugar de uma retomada inventiva da origem 'perdida': uma invenção que nada na história pode garantir, mas que tudo chama a realizar-se" (GAGNEBIN, 1994, p. 70). Eis aí um campo minado em que uma teoria crítica da memória representa o detector de metais. No emudecimento dos soldados retornados da Primeira Guerra Mundial, Benjamin constatara um processo de intensa desumanização "numa paisagem em que nada permanece inalterado, exceto as nuvens, e, debaixo delas, num campo de forças de torrentes e explosões destruidoras, o frágil e minúsculo corpo humano" (BENJAMIN, 1985, p. 214).

\section{Da memória social à memória cultural}

No nó que ata a experiência individual e o fenômeno social da memória encontramos sem dúvida o dedo de autores clássicos como Maurice Halbwachs e Ecléa Bosi. É inconteste a influência de trabalhos seminais como A memória coletiva ( $1^{a}$ edição em 1950) do primeiro, e Memória e sociedade: lembranças de velhos (1a edição em 1979), esta já em diálogo evidente com a obra do sociólogo francês.

Halbwachs construiu seu conceito de memória coletiva considerando a influência dos grupos sociais na construção das identidades. Erll (2011, p. 14-15) vai sintetizar a contribuição do sociólogo de viés durkheimiano no reconhecimento do peso das estruturas sociais sobre a memória, nos estudos sobre memória intergeracional e posteriormente na incorporação da transmissão cultural e da criação da tradição à memória coletiva. A memória individual, em sua perspectiva, é sempre enquadrada por essa memória coletiva cuja função é promover a coesão social. Assim a memória se constitui a partir de seus quadros sociais, ou seja, dos esquemas cognitivos que são apreendidos na socialização que é integra o indivíduo à ordem simbólica coletiva, na qual se opera qualquer ato de rememoração:

Não basta reconstituir pedaço a pedaço a imagem de um acontecimento passado para obter uma lembrança. É preciso que esta reconstrução funcione a partir de dados ou de noções comuns que estejam em nosso espírito e também no dos outros, porque elas estão sempre passando destes para aquele e vice-versa, o que será possível somente se tiverem feito parte e continuarem fazendo parte uma mesma sociedade, de um mesmo grupo (HALBWACHS, 2006, p. 39).

Lança-se assim um problema daqueles que estão no cerne das ciências sociais, o de pensar a fronteira entre indivíduo e cultura. Interessante pensar como o mesmo dilema se aplica também ao uso da 
informação enquanto um ato social. O trabalho de Ecléa Bosi (1979), pelo viés da psicologia social, sugere outros caminhos para reconhecer essa relação, dando um peso mais significativo ao traço individual, o que ressalta através de sua metodologia de pesquisa, de profunda empatia e reconhecimento da voz dos sujeitos que investiga, cuja escolha revela também a influência benjaminiana em seu trabalho, ao se propor ouvir e narrar as rememorações de velhos e operárias, personagens varridos das narrativas dominantes da sociedade. Esse compromisso entre a pesquisadora e aqueles que a ela confiam suas lembranças configura a base da proposta de entendimento da própria memória, percebida em seus deslizes e incompletudes (BOSI, 1979, p. 419), que a definem finalmente como tarefa, trabalho. Nesse ponto destaca-se a clareza com que a autora adota uma postura de observadora participante, realizando constante exercício de autocrítica. As implicações metodológicas para trabalhos desenvolvidos por discentes que envolvem entrevistas ou mesmo relatos biográficos são dignas de nota, como ficou evidente em alguns dos trabalhos produzidos como atividade final da disciplina.

Destacamos nos seminários realizados dois focos importantes de debate no veio destas obras, por consequência, em todo o campo dos estudos sobre memória. $O$ primeiro é a recorrente contraposição entre Memória e História. Halbwachs é taxativo em traçar uma divisão entre ambas:

No entanto, lidos nos livros, ensinados e aprendidos nas escolas, os acontecimentos passados são selecionados, comparados e classificados segundo necessidades ou regras que não se impunham aos círculos dos homens e que por muito tempo foram seu repositório vivo. Em geral a história só começa no ponto em que termina a tradição, momento em que se apaga ou se decompõe a memória social (HALBWACHS, 2006, p. 101).

Para ele a memória diz respeito ao vivido, ao que se guarda do passado porque interessa ao grupo que lembra, o oposto da História que trata de um passado de que não participamos e organiza sua narrativa num esquema ordenado cronologicamente para sua explanação didática Ricouer (2007, p. 407) ressalta justamente esse caráter escolar, concentrado nas datas e fatos do passado nacional. É preciso ter em mente que a construção desta oposição, especialmente na tradição ocidental, tem sua própria contextualização histórica. Aleida Assmann (2011, p. 53-67) apresenta uma boa síntese ao tratar da secularização do tempo e da memória. Entre os séculos XV e XVII, a profusão de narrativas genealógicas, forma de legitimação das cortes e dinastias, além das emergentes cidades e seus burgueses abastados. Novas disputas seriam lançadas com o advento da imprensa e a secularização que retirava da Igreja e da nobreza o monopólio sobre a recordação, enquanto emergia no Renascimento a consciência de uma ruptura entre passado e presente. A sistematização da crítica de fontes desenvolveu-se na batalha entre tradições rivais. Tratava-se de distinguir precisamente a História da Ficção, definindo uma técnica que assegura a imparcialidade e o 
compromisso com a Verdade. Na obra de Paul Ricoeur (2007, p. 182) encontramos uma análise densa e completa dessa problemática, incluindo aí uma longa nota sobre a crítica de fontes a partir do caso exemplar da Doação de Constantino, desmascarada por Lorenzo Valla, para daí discutir procedimentos e perícias, compilando aí os gestos que marcam o ofício do historiador do trato com as fontes à escrita. À luz das reflexões de eminentes historiadores como Bloch, Le Goff e Ginzburg ele propõe a noção de rastro como raiz comum entre testemunho e indício, a fim de alcançar os conceito de documento e prova. Há na historiografia um longo debate para que finalmente a crítica tenha levado ao reconhecimento de que a dúvida é instrumento de conhecimento e que se trata de avaliar a plausibilidade de uma dada interpretação.

Mas essa emergência nos interessa porque depende de uma ruptura, que Assmann traça ancorada em uma reflexão feita por Pomian²:

A história da construção da herança cultural é definida por uma série de rupturas: mudanças de crenças coletivas, modos de vida, reviravoltas tecnológicas, propagação de novos estilos de vida que substituíram estilos antigos. Cada ruptura remove certas classes de artefatos de suas funções e as direciona para o lixo, o abandono e o esquecimento (POMIAN, 1990 apud ASSMAN, 2011, p. 58)

O exemplo usado pela autora da secularização mosteiros na Inglaterra, com a incorporação de suas bibliotecas, sinaliza a passagem da memória da Igreja ao arquivo da Nação. O debate sobre as relações entre História e Memória, portanto, sugere um problema de investigação para o campo da Ciência da Informação na medida em que sua compreensão depende da história das instituições ou unidades de informação e de como sua criação e mudança articula os modos de guardar, organizar e dar acesso à mesma, nos mais diferentes suportes. E aqui evocamos o segundo foco, o Espaço, descrevendo assim um arco que retoma um tema caro tanto à tradição mnemônica - como Yates (2007) demonstra através da própria etimologia da palavra 'tópico' - à teoria crítica, se lembramos que a construção das Passagens propõe o périplo pela metrópole como de organizar reflexões e reminiscências. Como diz Ricoeur (2007, p. 59) "Os mais memoráveis lugares não pareceriam capazes de exercer sua função de memorial se não fosse também sítios notáveis no ponto de interseção da paisagem e da geografia". Para além dessa relação mais geral, devemos considerar adiante um tópico de particular relevância para os campos de estudo em destaque neste artigo, o dos lugares de memória ${ }^{3}$.

Halbwachs dedica o IV capítulo de A memória coletiva ao Espaço. Este Ihe transmite uma imagem de permanência e estabilidade, em contraponto à mutabilidade do tempo:

Assim, não há memória coletiva que não se desenvolva num quadro espacial. Ora, o espaço é uma realidade que dura: nossas impressões se sucedem, uma à outra, nada permanece em nosso

\footnotetext{
2 Do original POMIAN, K. Museum und kulturelles Erbe, In: KORFF; ROTH (Eds). Das historische Museum. Frankfurt: [s.n.], 1990. p. 62.

${ }^{3}$ Tenho realizado pesquisas que testam os limites deste conceito e consideram também sua possível interface com a museologia (GARCIA; PARANHOS, 2016).
} 
espírito, e não seria possível compreender que pudéssemos recuperar o passado, se ele não se conservasse, com efeito, no meio material que nos cerca. É sobre o espaço, sobre o nosso espaço - aquele que ocupamos, por onde sempre passamos, ao qual sempre temos acesso, e que em todo o caso, nossa imaginação ou nosso pensamento é a cada momento capaz de reconstruir - que devemos voltar nossa atenção; é sobre ele que nosso pensamento deve se fixar, para que reapareça esta ou aquela categoria de lembranças (HALBWACHS, 2006, p. 99-100).

Esse reconhecimento da importância da relação entre espaço e memória também marca presença no trabalho de Ecléa Bosi (1979, p.339), quando ela ressalta, por exemplo, que cada geração tem a sua cidade. Mas se o próprio Halbwachs (2006, p. 92) reconhece em alguns momentos que o espaço também muda - "Quando um grupo está inserido numa parte do espaço, ele a transforma à sua imagem, ao mesmo tempo em que se sujeita, e se adapta às coisas materiais que a ele resistem" ele tende a enfatizar essa dimensão mais fixa, rígida, de um espaço que assenta a memória a partir dessa duração. Numa Europa devastada por duas grandes guerras, e ainda sob a sombra de grandes nuvens de fumaça e barbárie que puseram a perder um projeto de civilização, tal insistência certamente pode ser interpretada também como escolha política. Chama a atenção inclusive seu recurso à literatura canônica para evocar o papel do espaço para o enquadramento social da memória:

Quando Balzac descreve uma pensão familiar, a casa de um avarento, e Dickens, o escritório de um tabelião, esses quadros já nos permitem pressentir a que espécie ou categoria social pertencem os homens que vivem dentro de um tal quadro. (HALBWACHS, 2006, p. 91)

O recurso à estabilidade, e finalmente à ênfase na coesão de uma comunidade, não está livre de contradições, como bem nota Pollack ao ressaltar que já se insinuava a dimensão de "negociação" entre o coletivo e o individual, mas finalmente constata uma inversão em relação ao sociólogo, pois "Numa perspectiva construtivista, não se trata mais de lidar com os fatos sociais como coisas, mas de analisar como os fatos sociais se tornam coisas, como e por quem eles são solidificados e dotados de duração e estabilidade" (POLLACK, 1989, p. 4). Sua crítica acaba por ir de encontro às escolhas metodológicas de Ecléa Bosi, identificando no relato oral uma ferramenta poderosa para revelar os conflitos inerentes à memória social:

Ao privilegiar a análise dos excluídos, dos marginalizados e das minorias, a história oral ressaltou a importância de memórias subterrâneas que, como parte integrante das culturas minoritárias e dominadas, se opõem à 'Memória oficial', no caso a memória nacional (POLLACK, 1989, p. 4).

O trabalho dos clássicos constitui assim um ponto de equilíbrio dentro da proposta da disciplina. Sua influência é mais que reconhecida, mas perpetua-se justamente porque tem densidade para receber a crítica 
que Ihes mantém vivos. Erll (2011, p.28, tradução nossa) demonstra exatamente isso ao analisar a influência de Halbwachs sobre a teoria da memória cultural do casal Jan e Aleida Assmann, que se "[...] apoia no insight de que há uma diferença qualitativa entre a memória coletiva baseada em formas cotidianas de interação e comunicação e [...] aquela mais institucionalizada assentada em rituais e mídias". Em sua explanação organizada, que resumimos, a memória comunicativa diz respeito ao experiencial, ao tempo de vida dos indivíduos, sendo estes igualmente capazes de lembrar e interpretar um passado comum, que circula no plano da oralidade. Já a memória cultural, objeto preferencial dos estudos de ambos, é atada a objetificações materiais e institucionalizada por rituais e formas que pretendem estabilizá-la, guardada e interpretada por especialistas treinados (xamãs, sacerdotes ou arquivistas, por exemplo). Assim, simplificadamente, a primeira é mais flexível, informal, negociável, enquanto a segunda tende à estabilidade, alcançada através de uso de portadores (monumentos, instituições) e mídias materialmente mais rígidas, das comemorações oficiais e do trabalho dos guardiões autorizados - dizem respeito, portanto, à construção social de versões formalizadas do passado. Obviamente essas distinções são esquemáticas e não são estanques, e de fato na contemporaneidade podemos observar como as fronteiras entre ambas são borradas pelo emprego dos recursos da internet, como as redes sociais, blogs e sítios de referência construídos colaborativamente. A profusão de noticiário forjado e sua interferência direta no debate público e na construção da memória é uma das evidências da relevância de se investigar o impacto de tecnologias e hábitos da produção, circulação e consumo da informação à luz da dinâmica cultural e dos estudos sobre memória. Como alerta Assmann em Espaços da Recordação:

Já que não há auto-organização da memória cultural, ela depende de mídias e de políticas, e o salto entre a memória individual e viva para a memória cultural e artificial é certamente problemático, pois traz consigo o risco da deformação, da redução e da instrumentalização da recordação. Tais restrições e enrijecimentos só podem ser tratados e acompanhados de crítica, reflexão e discussão abertas (ASSMANN, 2011, p. 19).

Neste livro a autora consolida importantes avanços em torno da teoria da memória cultural, cuja exploração mais detida deixaremos para um próximo artigo. Cabe aqui apresentar uma síntese que cumpre o objetivo de inseri-la no percurso dos debates realizados na disciplina, cumprindo mencionar que foi uma das obras recebidas com mais entusiasmo entre os discentes, e acabou figurando em vários trabalhos finais. Destacaremos dois pontos principais, que dizem respeito, essencialmente, às funções da memória. O primeiro trata da diferença entre memória como ars (arte) e como vis (potência), a primeira remetendo à mnemotécnica - "organização e ordenação formal do conhecimento" - e a segunda à tradição psicológica que "trata da interação da memória com a imaginação e a razão" (ASSMANN, 2011, p. 
22). Voltamos aqui, em outros termos, à dimensão reconstrutiva da memória e à diferença entre lembrança e recordação discutida desde Aristóteles. A primeira enfatiza a dimensão do armazenamento, a segunda, do processo de recordação: "O ato de armazenamento ocorre contra o tempo e o esquecimento, cujos efeitos são superados com a ajuda de certas técnicas. O ato de recordação, por sua vez, acontece dentro do tempo [...]" (ASSMANN, 2011, p. 34). Grosso modo a primeira remete ao espaço, a segunda, em contraponto, ao tempo. Neste caso constata-se o deslocamento entre o que foi arquivado e sua recuperação (ASSMANN, 2011, p. 33) - eventualmente se pode pensar do mesmo modo o processo entre a guarda e a recuperação da informação. Nesse deslocamento está um dos pontos de maior interesse se quisermos entender a interlocução entre a Ciência da Informação e estudos de memória e patrimônio.

Uma segunda distinção importante ainda se apresenta: a diferença entre a memória funcional e a memória cumulativa. Procurando assim ultrapassar a oposição memória x história tal como se apresenta em Halbwachs ou Pierra Nora, por exemplo, ela propõe pensar dois modos complementares de recordação. A memória funcional (ou habitada) é aquela vinculada a portadores vivos com perspectivas parciais, que procuram estabelecer pontes entre as diferentes temporalidades, e o fazem de modo seletivo, esquecendo algumas coisas e recordando outras enquanto intermedeia os valores pertencentes a grupos, instituições e mesmo indivíduos. A memória cumulativa (inabitada), por sua vez, é aquela que não pertence a um portador específico, capaz de armazenar aquilo que perdeu relação vital com o presente e é nitidamente distinto deste, e ambiciona abranger tudo sem exceção nem orientação seletiva, contendo o descartado, mas também o repertório de possibilidades perdidas. Seu modelo, ela esclarece, propõe que esta última seja o pano de fundo em relação ao proscênio da memória funcional, como reservatório de possibilidades de renovação. Nesse sentido, a memória cultural não replica o modelo da tradição, em sua dinâmica de atualização, porque contém ainda a potencialidade dessa reserva do que está arquivado (ASSMANN, 2011, p. 146-151; ERLL, 2011, p. 34-37). Essa perspectiva tem consequências diretas em como podemos pensar as políticas de memória e patrimônio, na medida em que se trata justamente de compreender essas diferentes funções e a forma com que se articulam, sobremaneira de um ponto de vista político. É uma saída para entender o jogo entre o instituído e o instituinte, o estruturado e o estruturante. Tal proposta parece ser promissora para as investigações que esperamos produzir e orientar dentro da linha de pesquisa, oferecendo um ponto de encontro entre as ciências sociais aplicadas e a história que valerá a pena explorar.

\section{Políticas de memória e patrimônio no espaço público: rememoração, esquecimento e comodificação da nostalgia}


Tal intuito ganha ainda mais sentido se levarmos em conta transformações históricas que redefiniram os campos da memória e do patrimônio a partir da modernidade. Em função do espaço que temos, de modo esquemático, indicamos que um primeiro movimento é aquele conectado ao romantismo e à busca das origens nacionais através da cultura. Em Samuel (1994), Assmann (2011) e Erll (2011) encontramos observações atinentes ao tema, percebendo o declínio da arte da memória concomitante à emergência da memória como potência capaz de promover a criação de identidade. Huyssen (2014, p.91) observa como a nostalgia e o culto às ruínas, desde o século XVIII, referiram-se a crescente percepção de irreversibilidade do tempo, que elas ajudam a demarcar quando assinalam a ausência (HARTOG, 2013, p. 204). Um segundo ponto de inflexão a se destacar é a Revolução Francesa. Foi no seu turbilhão que pretendia demarcar um corte definitivo no curso do tempo que se definiram as modernas instituições da memória cumulativa associada ao Estado Nacional, como arquivos e museus públicos, e simultaneamente a política de patrimônio. Se o poder republicano promove um verdadeiro banimento do Ancien Régime, que vai do esquecimento da linguagem da cortesia aos castelos demolidos e tesouros saqueados, produz uma mudança na ordenação do tempo e do espaço, instalando seus próprios lugares de memória (WEIRINCH, 2001, p. 161162).

É neste entroncamento que se encontram a retórica da perda (GONÇALVES, 2002) e o imperativo de preservar o que se define como herança. O presente revolucionário procede assim à invenção do passado nacional que Ihe convém e Ihe torna consequente, legitima: "O patrimônio torna visível, expressa uma certa ordem do tempo, na qual a dimensão do passado conta. Trata-se, porém, de um passado do qual o presente não pode ou não quer se desligar completamente" (HARTOG, 2013, p. 197). Como observa argutamente Assmann (2011, p. 52) tal foi o papel do museu histórico no século XIX, permitir a contemplação da História como unidade, representando o tempo como espaço - espaço de recordação, onde a memória é encenada. A sociedade escolhe o passado que deseja que tenha visibilidade no presente, e para fazê-lo apela ao que Lowenthal (1985, p. 160-161) denomina de "intimidade tangível" de relíquias e monumentos, ou seja, seu potencial para provocar um sentimento de proximidade, uma vez que tais artefatos pertencem ambiguamente ao presente e ao passado, e por isso tão favoráveis à construção de identidades nacionais.

A relação entre memória, patrimônio e identidade nacional é tema mais que consagrado, ao qual o tributo maior talvez seja a monumental coleção Les lieux de mémoire organizada por Pierra Nora entre 1984 e 1992, cuja influência é ressaltada por Erll (2011, p. 22-23). Ela se ergue sobre a sombra de uma ameaça, por assim dizer, pois num contexto em que se experimenta uma aceleração vertiginosa do tempo, vivemos um "momento de articulação onde a consciência da ruptura com o passado se confunde com o sentimento de uma memória esfacelada [...]" (NORA, 1993, p. 7). Daí, segundo o autor, a necessidade de se instaurar lugares 
da memória na sociedade contemporânea, uma vez que as bases tradicionais de sua preservação estariam minadas. À medida que a sensação de desaparecimento rápido e definitivo se difunde, amplia-se a obsessão pelo arquivo, pela retenção, em suportes exteriores, que torna memorável o "mais modesto dos vestígios" (NORA, 1993, p. 14). É dessa mesma obsessão nostálgica que trata Samuel em Teatros da memória. Entretanto, enquanto Nora pensa a memória como algo fabricado na forja do mito, do sagrado, do afetivo, do mágico - oposta, a seu ver, à história, operação intelectual, crítica, desmistificadora - Samuel, como vimos, reconhece a memória como forma de construir conhecimento, uma construção sujeita às intempéries do tempo em que estiver a ser feita.

A década de 1980 trouxe justamente uma multiplicação e descentralização do patrimônio, "categoria abrangente, senão devoradora" (HARTOG, 2013, p. 193), cujos excessos viriam a ser justamente criticados em trabalhos como os de Jeudy (1990). O nacional passou a conviver com o local, a diversidade dos grupos, e a emergência de novas perspectivas pelas quais "O Estado-nação não precisa mais impor seus valores, mas salvaguardar mais rapidamente o que, no momento presente, imediatamente, ou até na necessidade, é tido como 'patrimônio' pelos diversos atores sociais". (HARTOG, 2013, p.236). Aliás, também é significativo reparar que o boom de estudos sobre memória a partir dos anos 1980 e suas profundas consequências políticas sinalizam uma guinada transnacional que influencia "[...] a política nacional, os processos judiciais, as Comissões da Verdade e os debates populares de muitos países" e impregna a produção literária, as artes, etc. (HUYSSEN, 2014, p. 14-15).

Dentro da proposta da disciplina procuramos nos três últimos seminários lançar foco em trabalhos que, por diferentes vieses, apresentassem posições críticas e abordagens inovadoras em relação às políticas de memória e patrimônio no espaço público. Promovemos, com o mesmo intuito, a sessão comentada do filme Crônica da demolição e a palestra $O$ patrimônio nacional sob o imperativo estético (ver TAVARES, 2016), ambos dedicados a promover o debate dos temas a partir do cenário brasileiro ${ }^{4}$. Discutimos trabalhos que abordam esse cenário plural e que explicitam as disputas em torno dos campos tanto em âmbito nacional e latino-americano, como os presentes na coletânea organizada por Abreu e Chagas (2003), os trabalhos de Salgado (2013) e Silva (2002), quanto europeu, destacando aí conjunturas que problematizam as interpretações corriqueiras, como a reunificação da Alemanha (RÜSEN, 2014) ou o desmantelamento dos regimes socialistas reais no Leste Europeu (MACDONALD, 2013). Para alinhavar discussões teóricas fulcrais feitas no início do curso, os seminários finais também lançaram foco em discussões candentes que demandavam considerar os avessos e fraturas

\footnotetext{
${ }^{4}$ Ambos foram eventos promovidos pelo Grupo de Pesquisa Estopim (Núcleo de estudos interdisciplinares do Patrimônio Cultural), que coordeno conjuntamente com Rita Lages Rodrigues (Escola de Belas Artes UFMG), e os convidados, também colegas integrantes do grupo, foram respectivamente, Regina Helena Alves da Silva (Faculdade de Filosofia e Ciências Humanas - UFMG) e Denis Tavares (Centro Federal de Educação Tecnológica - Campus Timóteo), a quem agradeço pela contribuição, e aos demais membros pelas leituras e discussões que também reverberam neste texto.
} 
da memória, partindo da consideração de que "[...] na verdade não há nada que tenha mantido a lembrança tanto tempo em funcionamento quanto a catástrofe da destruição e do esquecimento que teve lugar em meados do século XX" (ASSMANN, 2011, p. 22). Na segunda metade do século XX a narração dos traumas históricos tornou-se um tema estratégico dentro do que acaba por definir-se como política da memória, enfrentando de um lado o efeito prolongando de graus de violência tão intensos que estariam além do que se poderia dizer, e de outro a ameaça do esquecimento intencionalmente promovido através do negacionismo. Márcio Seligmann-Silva reconhece que "[...] o testemunho de certo modo só existe sob o signo de seu colapso e de sua impossibilidade" (SELIGMANN-SILVA, 2008, p. 67). O caráter singular do testemunho do trauma reside entre a tarefa individual de narrar e a componente coletiva em que se busca realizar o trabalho de luto que possa ir além da memória de um passado que não passa.

Como não poderia deixar de ser, este e outros trabalhos como os de Huyssen (2014) e antes dele Pollack (1989) captam em profundidade a dimensão política implicada em disputas que envolvem tanto a produção da memória quanto do silêncio. Se a clivagem entre oficial e subterrâneo é relação de poder, quando se rompe o tabu, as memórias subterrâneas conseguem invadir o espaço público (POLLACK, 1989, p. 6). Há que se reconhecer aí diversas instâncias de 'negociação', incluindo agentes públicos, movimentos sociais, instituições e mídias (ERLL, 2011). Neste ponto cabe considerar as imbricações entre material e simbólico para entender a comodificação da nostalgia, na medida em que reconheçamos que o passado e a memória mesmo de acontecimentos traumáticos podem ser transformados em mercadoria, através da exploração emocional de testemunhos, da exposição fetichista de ruínas e relíquias ou mesmo de uma ação performática que em que se exibe o vazio (SIMINE, 2013; GIEBELHAUSEN, 2012; LEAHY, 2011).

\section{Considerações finais: uma avaliação da experiência}

Tais discussões revelam-se de grande valia ante uma profusão de objetos de estudo e pontos nodais do debate público que inescapavelmente orientam as atividades de uma linha de pesquisa em um Programa de Pós-Graduação. Ao atentar para os sujeitos que certa configuração do que é 'nacional' e 'oficial' soterra em toneladas de exclusão, negligência e esquecimento, investigações comprometidas com o reconhecimento desses sujeitos e seus direitos implicam em outras perspectivas teóricas e igualmente em novas orientações para as políticas públicas de informação, memória e patrimônio. Reforçamos também a interseção com o Direito e os Direitos Humanos como ponto de partida ético e político de nossas investigações, na medida em que intentamos superar qualquer tecnicismo em relação a como pensamos estas políticas a partir da condição do cidadão que delas participa. Num horizonte de expectativa, poderemos pensar que nossa tarefa é construir uma sociedade em que indivíduos e grupos sociais possam alcançar aquilo que 
Benjamin, na sua forma particular de profanação teológica, identificou como apokatastasis - a reunião das almas no paraíso que simboliza a redenção de todas as possibilidades até então derrotadas na História.

O engajamento dos discentes ao longo do curso, a boa qualidade dos debates e a assimilação de conceitos e leituras explicitada nos trabalhos finais são evidências de que a disciplina atingiu seus objetivos de forma exitosa. A reformulação do PPG-CI, como vimos no início deste artigo, não surgiu no vazio, e sim em terreno que já recebera as primeiras sementes, frutos das trajetórias de discentes e docentes ali atuando. É bom que se diga que o plantio é labor longo e extenuante, e que ainda está nas primeiras colheitas. Criar disciplinas nucleares para as linhas representa, para seguirmos com as metáforas, o melhor adubo para que tenhamos ótimas safras no futuro próximo.

\section{Referências}

ABREU, R.; CHAGAS, M. (Orgs). Memória e patrimônio: ensaios contemporâneos. Rio de Janeiro: DP\&A, 2003.

ARENDT, H. Entre o passado e o futuro. São Paulo: Perspectiva, 2007.

ASSMANN, A. Espaços da recordação: formas e transformações da memória cultural. Campinas, SP: Editora da Unicamp, 2011.

BENJAMIN, W. O narrador. In: BENJAMIN, W. Obras escolhidas I. São Paulo: Brasiliense, 1985.

BENJAMIN, W. Passagens. Belo Horizonte: Ed. UFMG; São Paulo: Imprensa Oficial, 2007.

BOSI, E. Memória e sociedade: lembranças de velhos. São Paulo: EDUSP, 1979.

ERLL, A. Memory in culture. Basingstoke: Palgrave Macmillan, 2011.

GAGNEBIN, J. M. Não contar mais? In: GAGNEBIN, J. M. História e narração em Walter Benjamin. São Paulo: Perspectiva/FAPESP; Campinas: Ed. Unicamp, 1994.

GARCIA, L. H. A. Derivas cartográficas: tecnologia aplicada à memória numa incursão pelos bares do Hipercentro de Belo Horizonte. In: CONFERÊNCIA SOBRE TECNOLOGIA, CULTURA E MEMÓRIA, 2011, Recife. Anais... Recife: LIBER;UFPE, 2011. v. 1. 10 p.

GARCIA, L. H. A.; PARANHOS, J. O Museu Clube da Esquina e os lugares da cidade: breve reflexão sobre ações museológicas no espaço urbano. Museologia e Patrimônio, v. 9, p. 134-152, 2016.

GIEBELHAUSEN, M. 'In the museum's ruins:staging the passage of time'. In: MACLEOD, S.; HANKS, L.; HALE, J. (Eds.). Museum making: narratives, architectures, exhibitions. London: Routledge, 2012. p. 234246. 
GONÇALVES, J. R. S. A retórica da perda: os discursos do patrimônio cultural no Brasil. 2. ed. Rio de Janeiro: UFRJ; Iphan, 2002.

HALBWACHS, M. A memória coletiva. São Paulo: Centauro, 2006.

HARTOG, F. Patrimônio e presente. In: HARTOG, F. Regimes de historicidade: presentismo e experiências do tempo. Belo Horizonte: Autêntica, 2013. p. 193-245.

HUYSSEN, A. Culturas do passado-presente: modernismos, artes visuais, políticas da memória. Rio de Janeiro: Contraponto: Museu de Arte do Rio, 2014. (ArteFíssil, 9).

JEUDY, H.-P. Memórias do social. Rio de Janeiro: Forense Universitária, 1990.

JULIÃO, L.; GARCIA, L.; SABINO, P. R.. O curso de Museologia da UFMG. Perspectivas em Ciência da Informação, v. 20, núm. esp., p. 1-8, out./dez. 2015.

KROISS, J. M. Ars memoriae, philosophy and culture: Frances Yates and after. In MAGEE, G. A. (Ed.). Philosophy and culture: essays in honor of Donald Phillip Verene. Charlottesville: Philosophy Documentation Center, 2002. p. 149-162.

LEAHY, H. R. Exhibiting absence in the museum. In: DUDLEY, Sandra et al. (Eds.). The thing about museums: objects and experience, representation and contestation: essays in honour of professor Susan $M$. Pearce. London: Routledge, 2011. p. 250-262.

LOWENTHAL, D. The past is a foreign country. Cambridge; New York: Cambridge University Press, 1985.

MACDONALD, S. Memorylands: heritage and identity in Europe today. Londres: Routledge, 2013.

NORA, P. Entre memória e história: a problemática dos lugares. Projeto História, São Paulo, v. 10, p. 7-28, dez. 1993.

POLLAK, M. Memória, esquecimento, silêncio. Estudos Históricos, v. 2, n. 3, p. 3-15, 1989.

PROPOSTA de reestruturação do Programa de Pós-graduação em Ciência da Informação da ECI/UFMG. Belo Horizonte, UFMG, 2016, 59 p.

RICOEUR, P. A memória, a história, o esquecimento. Campinas: UNICAMP, 2007.

RÜSEN, J.; JAEGER, F. A cultura da memoração na história da República Federal da Alemanha. In: RÜSEN, J. Cultura faz sentido. São Paulo: Vozes, 2014. p. 89-146.

SALGADO, M. Museos y patrimonio: fracturando la estabilidad y la clausura. Íconos-Revista de Ciencias Sociales, n. 20, p. 73-81, 2013.

SAMUEL, R. Theatres of memory: past and present in contemporary culture. London: Verso, 1994. v. 1 
SELIGMANN-SILVA, M. Narrar o trauma: a questão dos testemunhos de catástrofes históricas. Psicologia Clínica, Rio de Janeiro, v. 20, n. 1, p. 65$82,2008$.

SILVA, H. R. da. "Rememoração"/comemoração: as utilizações sociais da memória Revista Brasileira de História, São Paulo, v. 22, n. 44, p. 425438, 2002.

SIMINE, S. A.-de. Mediating Memory in the Museum: Trauma, Empathy, Nostalgia. Palgrave Macmillan, 2013.

SPENCE, J. D. O palácio da memória de Matteo Ricci. São Paulo: Companhia das Letras, 1986.

TAVARES, De. P. É esse conjunto que importa preservar, no seu todo: o patrimônio nacional sob o imperativo estético. Cadernos de Pesquisa do CDHIS, v. 29, p. 1-24, 2016.

WEIRINCH, H. Lete: arte e crítica do esquecimento. Rio de Janeiro: Civilização Brasileira, 2001.

YATES, F. A. A arte da memória. Campinas: Editora da Unicamp, 2007. 
Memória, patrimônio e informação: diálogos em uma

Luiz Henrique Assis Garcia disciplina nuclear 